\title{
Negative Feedback Regulation following Administration of Chronic Exogenous Corticosterone
}

\author{
Elizabeth A. Young, Seung P. Kwak and Juliet Kottak \\ Mental Health Research Institute and Department of Psychiatry, University of Michigan, Ann Arbor, MI 48109, USA.
}

\begin{abstract}
Administration of exogenous glucocorticoids is known to suppress the HPA axis and has been reported to occupy brain glucocorticoid receptors, eventually leading to down-regulation. To determine the effects of chronic corticosterone administration on HPA axis function, corticosterone was administered as both $25 \%$ and $50 \%$ corticosterone/cholesterol pellets. Rats were sacrificed 6 days after corticosterone pellet implantation. The $25 \%$ corticosterone pellets produced a small increase in morning corticosterone concentrations but no change in evening ACTH or corticosterone secretion. The $50 \%$ corticosterone pellets produced constant corticosterone concentrations of $5-6 \mu \mathrm{g} / \mathrm{dl}$, with no circadian variation in corticosterone, indicating inhibition of evening ACTH and corticosterone secretion. The $25 \%$ corticosterone pellets produced no significant decrease in thymus weight or in adrenal weight; $50 \%$ corticosterone pellets produced significant decreases in thymus weight and adrenal weight. Neither $25 \%$ nor $50 \%$ corticosterone pellets produced significant decreases in GR in hippocampus and cortex. The $50 \%$ corticosterone pellets treatment resulted in a decrease in anterior pituitary POMC mRNA levels, a decrease in baseline and $\mathrm{OCRH}$ stimulated ACTH release from the anterior pituitary, and a near complete inhibition of the AM and PM response to restraint stress. These results suggest that: 1) the HPA axis was able to adjust to the small increase in glucocorticoids produced by the $25 \%$ cort pellets with minimal disturbances in function and 2) $50 \%$ corticosterone pellets exert a significant inhibitory effect on stress and diurnal ACTH secretion which appears to be exerted at the pituitary as well as possible inhibitory effects on brain.
\end{abstract}

Glucocorticoid secretion is tightly controlled by an elaborate systems of checks and balances. In particular, the circulating concentrations of glucocorticoid 'feedback' to the controlling elements at multiple levels to turn off glucocorticoid secretion and consequently maintain the right range of glucocorticoids (1, 2). In man, administration of exogenous glucocorticoids clearly suppresses endogenous glucocorticoid secretion, resulting in adrenal atrophy with prolonged administration (3). Although exogenous glucocorticoids suppress cortisol or corticosterone and ACTH secretion, whether the site of feedback inhibition is the brain or pituitary is less clear. Dexamethasone, a synthetic glucocorticoid commonly used to monitor the 'normality' of the feedback circuits, appears to exhibit particularly profound inhibitory effects on the pituitary corticotrophs, and most data suggest that its primary site of negative feedback action is the pituitary $(4,5,6)$.

Circadian variation of corticosterone secretion is the normal pattern in a number of species including rat and man. The circulating levels of glucocorticoids show a circadian rhythm with peak and trough levels varying an order of magnitude $(3,7,8$, 9). The circadian variation in cortisol secretion is believed to reflect the circadian pattern of corticotropin releasing factor (CRF) from the paraventricular nucleus. Patients suffering from Cushing's disease, an ACTH secreting corticotroph tumor, generally demonstrate an absence of a circadian rhythm in ACTH or cortisol secretion, presumably because the tumor secretion is independent of $\mathrm{CRH}$ input and the high concentration of circulating glucocorticoids inhibit the neural elements responsible for CRH secretion which drives the circadian rhythm of cortisol. (3) In contrast, patients suffering from depression, a disorder that stimulates HPA axis activation through neural pathways, often demonstrate hypercortisolemia with elevated plasma glucocorticoid secretion at both the zenith and nadir of the circadian rhythm $(10-14)$. Whether these two different patterns of glucocorticoid secretion exert different effects on brain is not known.

Although brain glucocorticoid receptors (GR) are traditionally measured following adrenalectomy, the number of cytosolic GR can also be measured in non-adrenalectomized rats. When measured in intact rats this number of cytosolic receptors in hippocampus and cortex reflects the number of non-translocated receptors and can be used to determine the effects of in vivo manipulations such as acute stress, acute glucocorticoid administration or diurnal changes over the circadian rhythm $(15,16,17,18)$. Elegant studies by Miller et al. have characterized this method as a means of determining receptor occupation following administration of dexamethasone and corticosterone (17). Consequently, measurement of GR in adrenally intact rats may be useful as an index of glucocorticoid receptor occupation and provide information on whether a feedback signal is being exerted primarily at the brain. The following studies were undertaken to compare the effects of 
different doses glucocorticoids administered as a continuous corticosterone pellet on neural and peripheral elements of the HPA axis, including receptor activation. Corticosterone was chosen as the glucocorticoid to be administered since it has high affinity for both mineralocorticoid receptors (MR) and glucocorticoid receptors (GR) in the brain, in contrast to the synthetic ligand dexamethasone which binds poorly to MR. Previous studies by us and others had characterized the effects of the continuous release pellets used as replacement doses in adrenalectomized rats on plasma $\mathrm{ACTH}$ and corticosterone. and glucocorticoid and mineralocorticoid binding $(2,19,20)$. However, the plasma corticosterone levels achieved and the pattern of adaptation are likely to be different in adrenally intact animals from that shown in adrenalectomized animals. Consequently, the current studies were undertaken to explore how the HPA axis as a system adapts to an increase in glucocorticoids administered as a slow release corticosterone pellet, and at what levels of the HPA axis the feedback signal may be active.

\section{Results}

\section{Twenty-five per cent pellet experiments}

The effect of implantation of $25 \%$ corticosterone pellets were explored first. By day 6 following pellet implantation, plasma corticosterone levels were low in the a.m. of the cholesterol pellet rats $(1.55 \pm 0.6 \mu \mathrm{g} / \mathrm{dl})$ and very slightly increased in the corticosterone pellet rats $(3.4 \pm 0.8 \mu \mathrm{g} / \mathrm{dl})$. The plasma corticosterone levels in the p.m. were identical in the two groups $(12.7 \mu \mathrm{g} / \mathrm{dl}$ in both groups). Plasma ACTH and corticosterone data are shown in Figure 1. There was a significant a.m./p.m. difference in plasma ACTH, but no effect of corticosterone pellet treatment on plasma ACTH. Neither adrenal weight nor thymus weight, a sensitive index of integrated glucocorticoid concentrations in the periphery, was significant decreased in the rats receiving $25 \%$ corticosterone pellets. There were no differences in body weight between cholesterol and corticosterone pellet rats. Pituitary ACTH content and POMC mRNA levels were unchanged by $25 \%$ corticosterone pellet treatment. There were no significant effects of $25 \%$ corticosterone pellets on GR in hippocampus, cortex or hypothalamus (Table 1). The $\mathrm{K}_{\mathrm{d}} \mathrm{s}$ from Scatchard analysis were very similar for both groups in the cortex and hippocampus $(2.2 \pm 0.2 \mathrm{nM}$ for sham and $2.4 \pm 0.4 \mathrm{nM}$ cort in the cortex and $3.2 \pm 1.3 \mathrm{nM}$ for sham and $2.6 \pm 0.7 \mathrm{nM}$ in the hippocampus). There were no detectable mineralocorticoid receptors in any brain region from either group of rats.

Fifty per cent corticosterone pellets

Implantation of $50 \%$ corticosterone pellets resulted in very different hormonal profiles than $25 \%$ pellets. The data are shown in
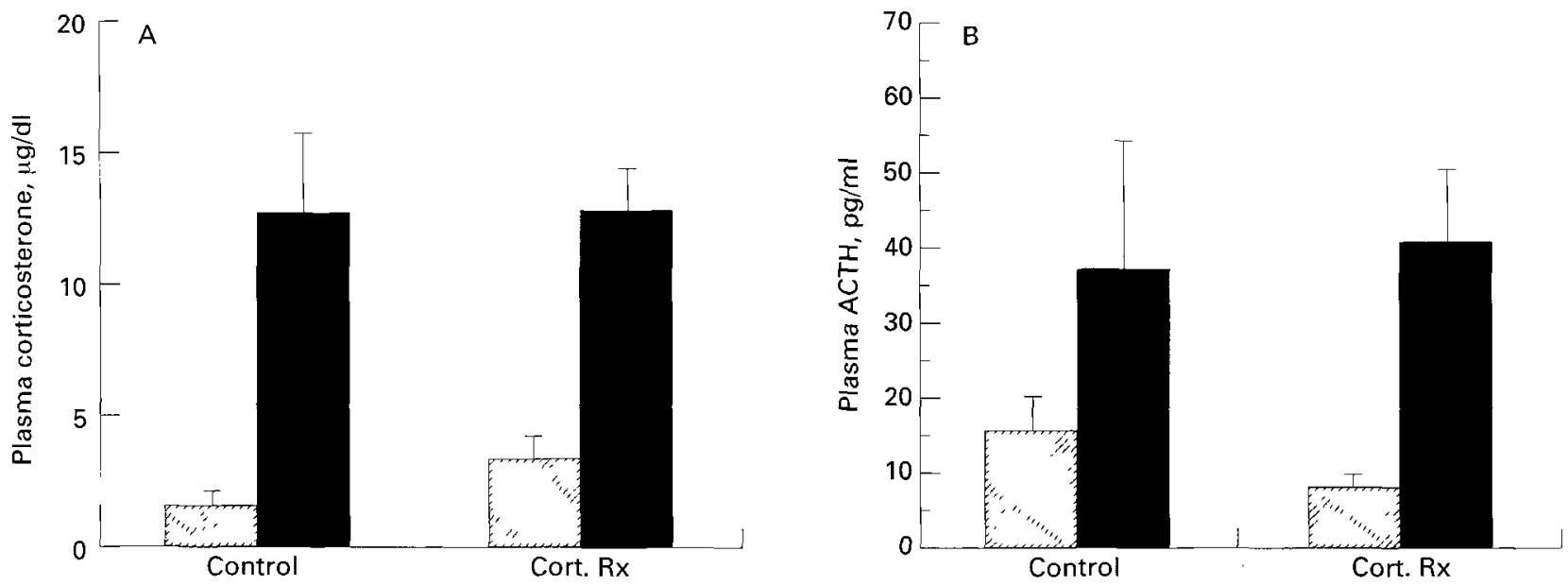

FIG. 1. Comparison of plasma corticosterone (panel A) and plasma ACTH (panel B) in the morning (a.m.) and evening (p.m.) in sham and 25\% corticosterone treated rats 6 days following implantation of these pellets. The $25 \%$ cort pellet treated rats show a small increase in cort in the a.m. (panel A), which is accompanied by a small decrease in plasma ACTH (panel B) at the same time. No change in plasma corticosterone or ACTH is scen in the p.m. in the cort treated rats. $\mathbf{a}$ a.m.; p.m..

TABLE 1. Comparison of $25 \%$ and $50 \%$ Corticosterone Treated Rats and their Respective Sham Treated Controls on HPA Axis and Brain GR Binding Measures.

\begin{tabular}{|c|c|c|c|c|}
\hline & $25 \%$ Control & $25 \%$ Cort Pellet & $50 \%$ Control & $50 \%$ Cort Pellet \\
\hline POMC mRNA (OD) & $116 \pm 27$ & $121 \pm 21$ & $109 \pm 11$ & $80 \pm 11^{*}$ \\
\hline Mean cortex GR fmoles/mg protein + & $166 \pm 25$ & $146 \pm 11$ & $155 \pm 26$ & $140 \pm 14.4$ \\
\hline Mean hippocampus GR fmoles mg protein + & $110 \pm 16$ & $104 \pm 18$ & $85.2 \pm 14$ & $84.6 \pm 20.6$ \\
\hline Mean hypothalamus GR fmoles/mg protein + & $68.7 \pm 5.1$ & $77.3 \pm 8.3$ & $58.4 \pm 8.8$ & $49.4 \pm 8$ \\
\hline
\end{tabular}

* = significantly different from the matched controls by ANOVA ( $50^{\prime \prime}$ cort. experiment $) ;+=$ Mean of both a.m. and p.m. values, $\mathrm{n}=12$ per group. 
Fig. 2, panel A. By day 6 , the $50 \%$ pellet rats clearly demonstrate an inhibition of the normal p.m. rise in corticosterone, suggesting a flat circadian rhythm of corticosterone, while cholesterol pellet controls demonstrate a normal circadian rhythm of corticosterone. The plasma ACTH data also demonstrated a clear circadian rhythm of ACTH in the rats treated with cholesterol pellets. (Fig. 2 panel $\mathrm{B}, \mathrm{F}=9.1$, df $=1, \mathrm{P}=0.0074$ ). Six days following pellet implantation, there was a significant effect of $50 \%$ corticosterone pellets on plasma ACTH ( $F=17, \mathrm{df}=1, \mathrm{P}=0.0006)$. The corticosterone pellet treatment was able to completely block the p.m. rise in ACTH (significant interaction of treatment and time of day, $F=9.8, P=0.0057)$. Peripheral indices of integrated corticosterone secretion, thymus weight and adrenal weight, were significantly decreased in the $50 \%$ corticosterone pellet treated rats (thymus weight, ANOVA $F=16.5, \mathrm{df}=1, \mathrm{P}=0.0002$ for corticosterone treatment; adrenal weight ANOVA $\mathrm{F}=82.6$, $\mathrm{df}=1, \mathrm{P}=0.0001$ for corticosterone treatment). Anterior pituitary ACTH content was not significantly decreased, although proopiomelanocortin (POMC) mRNA levels were significantly decreased in corticosterone treated rats (ANOVA, corticosterone $\mathrm{F}=10.7, \mathrm{df}=1, \mathrm{P}=0.0025$; no a.m. versus p.m. differences and no significant interaction). Brain glucocorticoid receptors (GR) were assayed in the hippocampus, cortex and hypothalamus, to determine if glucocorticoid pellets were able to lead to significant occupation of cytosolic GR. Despite this clear indication of increased mean glucocorticoid concentrations in corticosterone pellet rats, there was no decrease in cytosolic GR in any regions of brain. Even in the a.m., when corticosterone concentrations were significantly elevated in the $50 \%$ corticosterone pellet rats compared to cholesterol treated rats, no significant decrease in GR was observed. No differences in $\mathrm{Kd}$ were seen between control and corticosterone treated rats (Cortex $=0.13 \mathrm{nM}$ for each group, Hippocampus $=1.0 \mathrm{nM}$ for each group; $\mathrm{Bmax}=$ Cortex 176 is 168: Bmax Hippocampus 176 vs 171). Again, in none of the regions was an $\mathrm{MR}$ binding signal detectable in either cholesterol or corticosterone treated rats.

A second group of rats were treated with $50 \%$ corticosterone pellets and were sacrificed in the morning of day 6. This experiment used a two-by two design, with half the rats receiving corticosterone pellets and the other half inactive cholesterol pellets and half of each group of rats received dexamethasone in the drinking water. Consequently, it is possible to compare each glucocorticoid treatment as well as examine the additive effects of both treatments. In this experiment, CRH mRNA in the PVN and GR and MR mRNAs in the hippocampus were also measured. Again, a.m. plasma corticosterone was increased in the corticosterone treated animal to $6.8 \pm 1.4$. Significant decreases in plasma ACTH $(\mathrm{P}=0.05)$ and thymus weight $(\mathrm{P}=0.001)$ were observed in both $50 \%$ corticosterone pellet treated and in acute dexamethasone treated rats. Receptor binding studies again demonstrated no significant decrease in GR number in hippocampus or cortex in 50\% corticosterone treated rats, but a significant decrease was observed in rats given dexamethasone in their drinking water (cort $\mathrm{Rx} F=0.4, \mathrm{df}=1$, $\mathrm{p}=$ n.s.; dex $\mathrm{Rx} F=15, \mathrm{df}=1, \mathrm{P}=0.0004)$. A similar decrease was seen in both cortex and hippocampus (3-Way ANOVA, no significant difference between brain region). Neither corticosterone pellet treatment nor acute dex treatments affected GR or MR mRNA in hippocampus ( Table 2). There was no significant effect of corticosterone pellet treatment on CRH mRNA in the PVN, but there was a significant effect of dex treatment ( Table 2 , Cort $\mathrm{Rx} F=0.9, \mathrm{df}=1, \mathrm{p}=\mathrm{ns}$; dex $\mathrm{Rx} F=9.3, \mathrm{P}=0.007$ ). The pituitaries from these rats were processed into single cell suspensions and then challenged with $1 \mathrm{nM}$ ovine corticotrophin releasing factor (oCRF). The pituitaries from 3 rats were pooled for these challenge studies. A total of 6 animals per group was examined and data are the means of both pools. Anterior pituitary cell preparations from the 4 groups of rats were challenged with $1 \mathrm{nM}$ oCRH. The data are shown in Fig. 3. Chronic corticosterone pellets reduced the baseline and oCRH stimulated ACTH secretion, but the responsiveness to oCRH, expressed as per cent unstimulated baseline is the same in both groups $(150 \%)$. Acute dex treatment and the combination of acute dex plus cort pellets produced decreases in both ACTH
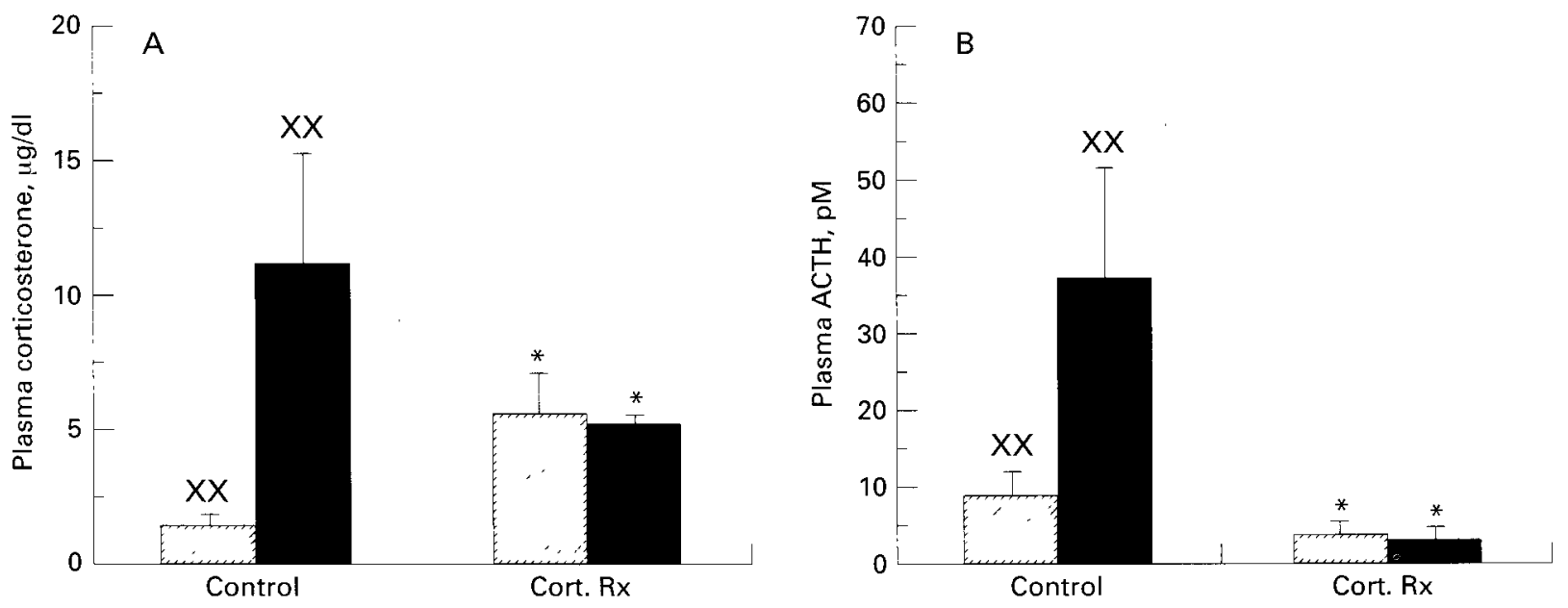

FIG. 2. Comparison of plasma corticosterone (panel A) and ACTH (panel в) in morning and evening in sham and 50\% cort pellet treated rats. The cort data is shown 6 days following pellet implantation. A flat rhythm of corticosterone is observed by day 6 , with a significant increase in plasma corticosterone in the a.m. $(P=0.002)$ and a significant decrease in the p.m. $(P=0.04)$ in $50 \%$ corticosterone pellet treated rats. The ACTH data demonstrate significantly lower plasma ACTH both morning and evening in corticosterone treated rats $(P=0.006)$ as well as elimination of the evening circadian rise in $\mathrm{ACTH}$ in the corticosterone treated rats. ${ }^{*}=$ significantly different from control; $\mathrm{XX}=$ significant a.m. vs p.m. difference. 
TABle 2. Summary of Data from Repeat 50\% Corticosterone Pellet Experiment Plus and Minus Acute Dexamethasone.

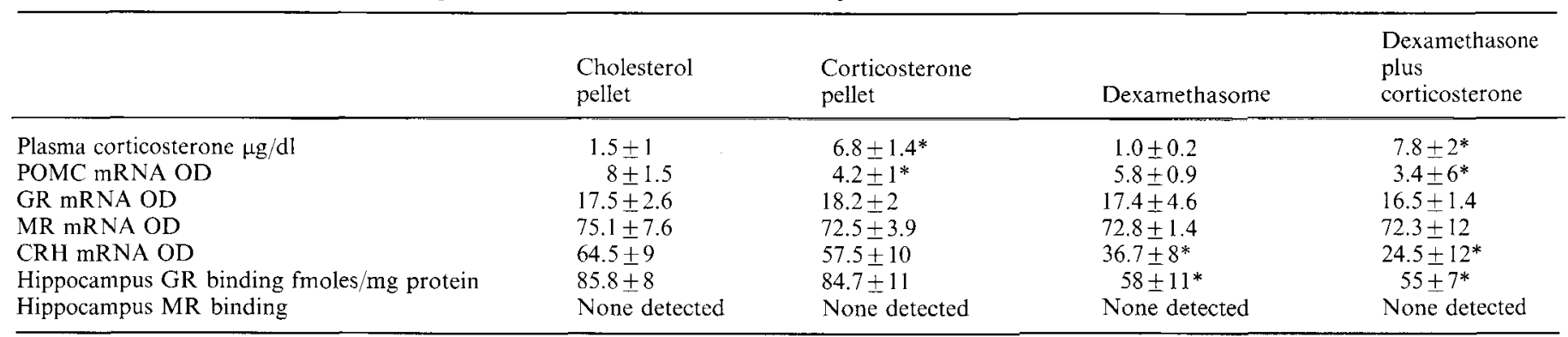

* Significantly different from cholesterol pellet by ANOVA.

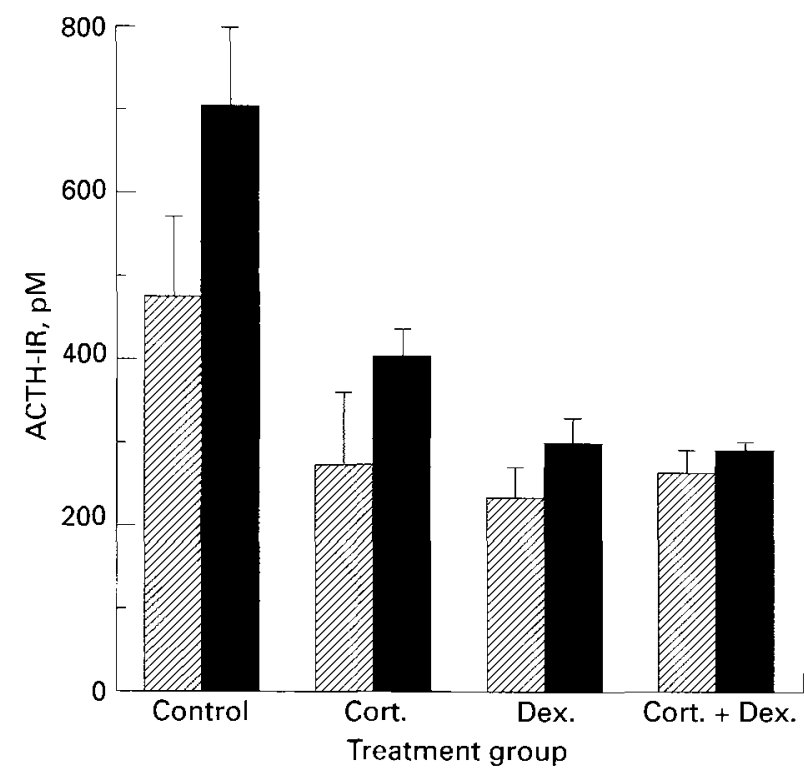

FIG. 3. Anterior pituitary cell baseline secretion and response to oCRH following in vivo treatment with either $50 \%$ corticosterone pellets, dexamethasone in the drinking water, or the combination. All 3 treatments result in a decrease in baseline $\mathrm{ACTH}$ secretion in comparison to placebo treated control rats. The percent increase in ACTH secretion following oCRH stimulation is similar between control and 50\% corticosterone treated rats $(150 \%)$. Dexamethasone treatment appears to inhibit responsiveness to oCRH $(127 \%$ and $110 \%$ for dex and dex plus cort rats respectively). baseline; $\mathbf{0}+\mathrm{oCRF}$

secretion and responsiveness to oCRH, expressed as percent unstimulated secretion ( $127 \%$ and $110 \%$ respectively).

To determine if the failure of $50 \%$ corticosterone pellets to produce a decrease in CRH mRNA might occur because corticosterone was too weak an agonist at GR, a comparison of acute dexamethasone and acute corticosterone was undertaken. Because of the high concentration of corticosterone in this solution $(200 \mu \mathrm{g} / \mathrm{ml})$ each rat consumed approximately $1.6 \mathrm{mg}$ of corticosterone. The plasma corticosterone concentration in rats receiving corticosterone in the drinking water was elevated to the concentration normally seen during the peak of the circadian rhythm in the corticosterone treated rats (Table 3 ) confirming an adequate intake of corticosterone (One way ANOVA $\mathrm{F}=19.6, \mathrm{P}=0.0001$; $\mathrm{P}<0.05$ Fisher PLSD post-hoc water $v s$ cort). Likewise, the plasma corticosterone concentrations in the dexamethasone treated rats were suppressed below the very low morning baseline
(Table 3) although this was not a significant decrease by post-hoc testing. Both dexamethasone and corticosterone treated rats demonstrated decreased plasma ACTH in comparison to control rats (One way ANOVA, $\mathrm{F}=6.4, \mathrm{P}=0.0096$; Fisher PLSD posthoc testing dex vs water $\mathrm{P}<0.05$ and $\mathrm{P}<0.05$ for cort $v s$ water). Thymus weight was significantly decreased in dexamethasone treated rats (Table 2, $\mathrm{P}=0.009$ ). Both acute corticosterone treated and acute dexamethasone treated rats demonstrated significant decreases in GR binding in hippocampus (ANOVA $F=3.5$, $\mathrm{P}=0.05$; post - hoc Fisher PLSD $\mathrm{P}<0.05$ for $\operatorname{dex} v s$ water and for cort $v s$ water). The decreases in glucocorticoid binding seen in the cortex in dexamethasone and corticosterone treated rats were not significant by ANOVA. Both glucocorticoid treatments also resulted in decreased $\mathrm{CRH} m \mathrm{mNA}$ in the PVN $(\mathrm{F}=5.2, \mathrm{P}=0.03$ for treatments; $\mathrm{P}<0.05$ by Fisher PLSD post-hoc testing water vs cort and water $v s$ dex). Neither treatment resulted in a significant decrease in anterior pituitary POMC mRNA.

Finally, two additional experiments were undertaken. The first was conducted to determine whether implantation of a sham pellet may have altered our ability to detect the effects of $50 \%$ corticosterone treatment. Hippocampal and cortical GR were measured in a third group of $50 \%$ corticosterone treated rats and compared to a group of unhandled control rats. Again, identical numbers of GR were seen in unhandled control and $50 \%$ corticosterone treated rats in both hippocampus and cortex. To increase the statistical power to detect small decreases in GR, the receptor binding data from all 3 studies were combined for statistical analysis and still no significant decrease in GR number was observed in hippocampus or cortex (Hippocampus Control= $82.5 \pm 11$, Hippocampus Cort $=85.8 \pm 16$; Cortex Control $=$ $85 \pm 13$, Cortex Cort $=94 \pm 10$ ). The final experiment evaluated whether the lack of effect of $50 \%$ corticosterone pellet treatment on GR binding was specific to the brain, or also occured in peripheral tissues. We examined GR binding in spleen, thymus and anterior pituitary. No significant decreases in GR binding were seen in any tissue examined, whether central or peripheral.

\section{Effect of $50 \%$ conticosterone pellets on stress-induced ACTH secretion}

Since the $50 \%$ corticosterone pellet rats demonstrated an inhibition of diurnal ACTH secretion, the ability of this treatment to affect restraint stress induced ACTH secretion in both the a.m. and p.m. was explored. In this study, each rat was studied in the a.m. and p.m. both before and after $50 \%$ corticosterone pellet implantation. The plasma ACTH data for 5 and 30 mins of restraint stress are shown in Fig. 4 . As can be seen, there was a 
TABLE 3. Effect of Acute Dexamethasone and Acute Corticosterone on Central and Peripheral HPA Axis Markers.

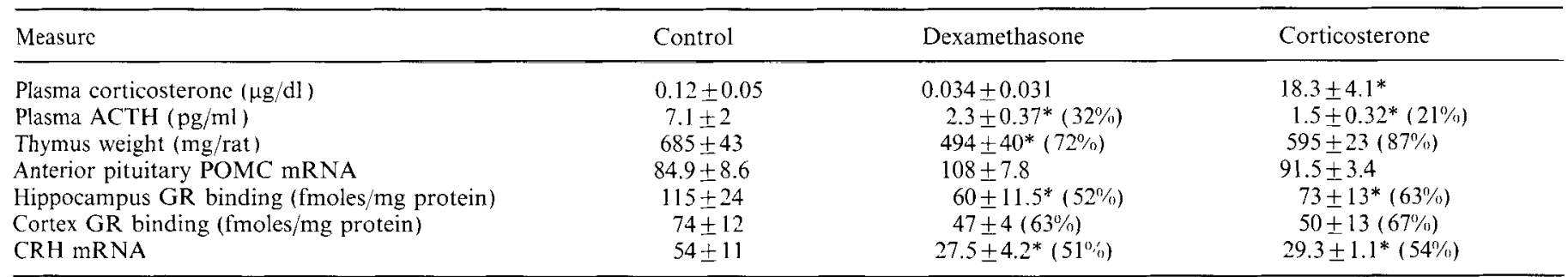

* Significantly different from control by ANOVA.
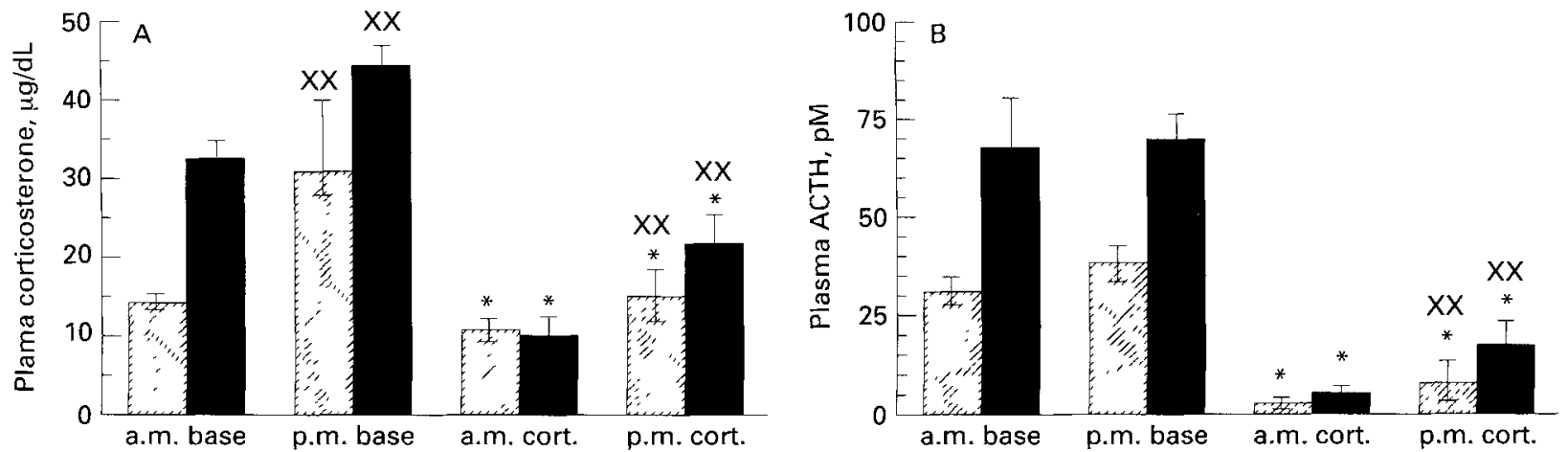

FIG. 4. Comparison of ACTH (panel A) and corticosterone (panel B) response to a.m. and p.m. restraint in rats before (baseline) and following (pellet) implantation of $50 \%$ corticosterone pellets. There is no difference in the a.m. vs p.m. ACTH response to restraint stress before $50 \%$ corticosterone pellet treatment. Following implantation, a profound inhibition of ACTH secretion is seen in both the a.m. and p.m.. The corticosterone data also demonstrate an extremely small adrenal response to this stress following $50 \%$ corticosterone pellet treatment. ${ }^{*}=$ significantly different from baseline; $\mathrm{XX}=$ significant a.m. vs p.m. difference. $5 \mathrm{~min} ; \mathbf{\square} 30 \mathrm{~min}$.

clear ACTH response to restraint in both the a.m. and p.m. before pellet implantation (baseline). There was no diurnal variation in the ACTH response to restraint. Following implantation of $50 \%$ corticosterone pellets, both the a.m. and p.m. ACTH response to restraint was greatly inhibited. There was a significant a.m. vs p.m. ACTH response to restraint stress in the corticosterone treated rats (2-way ANOVA, $F=5.4, \mathrm{df}=1, \mathrm{P}=0.03$ for a.m. vs p.m.). The corticosterone data for the same animals are shown in the lower panel. Again, only a very small corticosterone response to restraint is seen in either the a.m. or p.m. following implantation of the corticosterone pellet. Again, there was a significant diurnal difference in the corticosterone response to restraint in both the baseline and corticosterone treated groups (2-way ANOVA, $\mathrm{F}=8.0, \mathrm{df}=1, \mathrm{P}=0.009$ for a.m. vs p.m.).

\section{Discussion}

The data presented here describe two different doses of chronic corticosterone that lead to different plasma corticosterone profiles and different adaptations on the part of the HPA axis. The $25 \%$ corticosterone pellets resulted in an increase in the morning corticosterone but preservation of the circadian rhythm of corticosterone while $50 \%$ corticosterone pellets produced an inhibition of the normal evening rise in plasma corticosterone, suggesting a flat circadian rhythm of corticosterone, although a shift in timing of the peak cannot be excluded with only two time points of sampling. In both the $25 \%$ and $50 \%$ pellet experiments, the cholesterol pellet controls rats demonstrated morning corticos- terone concentrations of $1.5 \mu \mathrm{g} / \mathrm{dl}$; the $25 \%$ pellet rats demonstrated morning corticosterone concentrations of $3.4 \mu \mathrm{g} / \mathrm{dl}$, while the $50 \%$ corticosterone pellet rats demonstrated morning corticosterone concentrations of $5.6 \mu \mathrm{g} / \mathrm{dl}$. The small increase in a.m. plasma corticosterone in the $25 \%$ corticosterone pellet rats did not lead to any change in the evening plasma ACTH or corticosterone secretion, while the additional increment in plasma corticosterone in the $50 \%$ corticosterone pellet rats led to a significant suppression of a.m. plasma ACTH concentrations, and a suppression of the diurnal rhythm of ACTH and corticosterone secretion. The $25 \%$ pellets did not lead to a significant decrease in thymus weight or adrenal weight. Similarly, there were no changes anterior pituitary ACTH content nor in POMC mRNA levels. These data suggest that the HPA axis was able to adapt to the small increase in morning corticosterone with few, if any, consequences. This was in clear contrast to the effects of $50 \%$ pellet administration, which led to a significant decrease in both thymus weight, and adrenal weight as well as a decrease in anterior pituitary POMC mRNA levels and the suppression of the evening circadian peak of $\mathrm{ACTH}$ and corticosterone secretion. However, even the $50 \%$ corticosterone pellet treatment did not lead to a decrease in ACTH anterior pituitary content. In the $50 \%$ corticosterone pellet treated rats, both release, as reflected by plasma ACTH concentrations, and biosynthesis, as reflected by POMC mRNA levels, were decreased in parallel, which could explain the lack of change in ACTH stores. This suggests that steady state hormone stores are not the best indication of the activity of an endocrine gland. 
In contrast to the clear indication of increased corticosterone concentrations in the peripheral measures of HPA axis function, there was no indication that either $25 \%$ or $50 \%$ corticosterone pellets produced any decrease in available GR (occupation or down-regulation) in hippocampus, cortex, hypothalamus, spleen or thymus. In second experiment $G R$ and $M R$ mRNAs in the hippocampus were measured and there was no indication that the chronic cort treatment produced receptor down-regulation at the mRNA level. This suggests that relatively high concentrations of circulating glucocorticoids may be necessary to produce significant occupation of Type II receptors, and that the corticosterone pellets never achieved this concentration. This hypothesis is supported by the data of Spencer et al. (18) examining GR and MR occupation in intact rats during the peak and nadir of the circadian rhythm, as well as data from Reul et al examining the effects of acute stress on MR and GR occupation $(21,22)$. In adrenally intact rats the increase in corticosterone from to $20 \mu \mathrm{gdl}$ in the evening from $1 \mu \mathrm{gdl}$ in the a.m. resulted in a $25 \%$ decrease in GR in the hippocampus and cortex. Given that the increases in plasma corticosterone concentrations resulting from the $50 \%$ corticosterone pellets was only $25 \%$ of the normal diurnal change, a decrease of only $6 \%$ may be far too small to produce a detectable signal. Alternatively, the changes induced by chronic glucocorticoid treatment may be compensated by changes in the biosynthesis, half-life or distribution of receptors, so that available cytosolic receptors do not appear to produce meaningful information following chronic treatment. Finally, the inability to detect decreases in GR and MR mRNA levels in whole hippocampus may reflect regional specific regulation of these mRNAs in hippocampal subfield, as already been reported for adrenalectomy induced increases (23). Despite our inability to demonstrate any effects of corticosterone pellet treatment on GR, the small increase in glucocorticoids with this treatment resulted in inhibition of anterior pituitary POMC $\mathrm{mRNA}$ levels and inhibition of plasma ACTH secretion in both the a.m. and p.m.

In the Spencer et al. study (18), a small number of MR could be detected in adrenally intact rats in the a.m. but not the p.m. In these current studies, MR could not be detected in any groups of rats, even the control rats with plasma corticosterone concentrations of $1.5 \mu \mathrm{g} / \mathrm{dl}$ or lower. This suggests either that these receptors are present in extremely small numbers in intact rats of this strain, or that these low levels of corticosterone are capable of fully occupying these receptors (21). In neither dexamethasone experiment could we detect MR binding in the dexamethasone treated groups. This is rather surprising since Spencer et al. (15) demonstrated that this same dose of dexamethasone was able to lead to an increase in MR signal in non-adrenalectomized rats. Since the data of that group suggest that higher doses of dexamethasone in the drinking water will decrease MR binding, it may be that in the studies of Spencer et al. (15), the rats consumed less dexamethasone than in either of these two experiments. Because occupied MR in the nucleus cannot rebind steroid hormones in exchange assays (15), we cannot determine if the failure to detect these receptors in cytoplasm results from only a small total pool of receptors or whether the majority of receptors are occupied and translocated to the nucleus. It should be noted that the studies of Reul et al. $(22,24,25)$ found that the acute injection of dexamethasone produced no increase in MR binding for a full $24 \mathrm{~h}$, even though the injection blocked the evening rise in corticosterone. Chronic dosing of corticosterone produced an increase in MR binding as well as a decrease in GR binding. Although GR and MR mRNA levels may be helpful in determining whether receptor down-regulation has occurred, our previous studies found no change in MR or GR mRNA levels in response to injection of corticosterone in sesame oil, a paradigm (20) a paradigm previously demonstrated to produce glucocorticoid receptor down-regulation (26). However, it is possible that regional changes in GR or MR mRNA levels in hippocampal subfields may occur as has been demonstrated for adrenalectomy (23). Finally, steady state mRNA levels do not always reflect changes occuring at the level of transcription and translation.

Chronic corticosterone treatment had no effect on CRH mRNA levels in the PVN, while acute dexamethasone administration did. Since dexamethasone is a synthetic steroid with a higher affinity for GR than corticosterone, it was possible that corticosterone is too weak of a GR agonist to affect binding and CRH mRNA. To test this hypothesis, we administered a high dose of corticosterone overnight in the drinking water similar to that given by Miller and colleagues (17). These experiments were designed to demonstrate that a higher plasma corticosterone concentration $(18 \mu \mathrm{g} / \mathrm{dl})$ was capable of affecting the central measures of glucocorticoid inhibition, since these effects were not seen with $50 \%$ corticosterone pellets $(5-6 \mu \mathrm{g} / \mathrm{dl}$ ). The plasma concentration of corticosterone achieved by this paradigm is similar to the plasma concentration during the circadian peak of corticosterone secretion. In the acute dexamethasone and acute corticosterone experiment, both steroids demonstrated clear inhibitory effects on basal ACTH secretion, even though the morning is normally the time of the trough in ACTH secretion in rats. Neither treatment led to a decrease in anterior pituitary POMC mRNA, probably because $12 \mathrm{~h}$ is too short of a time to lead to significant decreases in a large pool of $\mathrm{mRNA}$. Both acute treatments were able to decrease CRH mRNA in the PVN; the decrease seen with dexamethasone treatment was similar in both experiments $(50 \%$ of control). Finally, the comparisons between acute and chronic treatments involve both differences in absolute doses of steroids and differences in plasma corticosterone levels as well as differences in time course, so it is not possible to ascribe differences in HPA axis profiles produced by these different treatments to time course or dose alone.

The $50 \%$ corticosterone pellet treated rats demonstrated clear inhibition of HPA axis but the sites of this inhibition are less clear. Corticosterone treatment blocks the normal evening rise of corticosterone, suggesting at least a pituitary site of inhibition. The decrease in POMC mRNA further supports inhibitory effects at the pituitary. The decrease in baseline ACTH secretion and decreased ACTH response to $1 \mathrm{nM}$ CRF in $50 \%$ corticosterone pellet treated rats suggest that the pituitary is an important site of the negative feedback on ACTH secretion, particularly by decreasing readily releasable stores of ACTH. The similar response to oCRF, expressed as percent baseline, between anterior pituitaries from cholesterol treated and corticosterone treated rats suggest that the changes do not involve changes in pituitary CRF receptors. Despite a clear decrease in POMC $m$ RNA, there were no changes in CRH mRNA in the PVN in the $50 \%$ corticosterone treated animals. Both CRH and vasopressin in the parvocellular division of the PVN are known to be secretagogues in the HPA axis. The current studies do not address vasopressin mRNA levels in the PVN because there are a large number of magnocellular vasopressin neurons within the micropunch area and these magno- 
cellular neurons are not sensitive to glucocorticoid regulation (27). Thus it is possible that changes in vasopressin mRNA levels occur within the parvocellular division in our $50 \%$ corticosterone treated rats. Given the clear inhibition of the HPA axis, including both circadian and stress induced ACTH secretion, the decrease in ACTH secretion from anterior pituitary in vitro, and the decrease in anterior pituitary POMC mRNA levels resulting from $50 \%$ corticosterone pellet treatment, the pituitary as a site of inhibition has some experimental support.

Recent studies by Akana et al. (28) used a similar corticosterone pellet regimen of $20 \%, 40 \%$ and $80 \%$ corticosterone pellets. They observed with the $20 \%$ and $40 \%$ corticosterone pellets results that are comparable to our results with $25 \%$ and $50 \%$ corticosterone pellets on thymus weight, adrenal weight and peripheral plasma corticosterone concentrations, including the suppression of the circadian rhythm of corticosterone in the $40 \%$ corticosterone treated animals but not in the $20 \%$ corticosterone treated animals. They also observed a decreased ACTH and corticosterone response to restraint stress in the a.m. with $40 \%$ corticosterone pellet treatment. The same stress repeated in the p.m. resulted in an inhibition of the ACTH stress response only in the $80 \%$ corticosterone pellet group, demonstrating an a.m./p.m. difference in the effectiveness of the $40 \%$ corticosterone pellets in inhibiting HPA axis activation by stress. Our data with $50 \%$ corticosterone pellets demonstrate clear inhibition of the stress response in both the a.m. and p.m.. Differences between our data and their data probably result from higher plasma corticosterone levels (average $6.2 \mu \mathrm{g} / \mathrm{dl}$ ) in the $50 \%$ corticosterone treated rats compared to their $40 \%$ corticosterone treated rats $(4.0 \mu \mathrm{g} / \mathrm{dl})$.

In conclusion, exogenous $50 \%$ corticosterone pellets caused profound inhibition of the HPA axis, but did lead to no detectable occupation of GR in the hippocampus, cortex, thymus or spleen. Thus it appears that examining the number of available cytosolic glucocorticoid receptors was not informative in this paradigm, probably because of the long term nature of the treatment. Given the data suggesting clear inhibition of the stress response in vivo, and inhibition of the anterior pituitary secretion in vitro, both pituitary and brain appear to be likely sites of the inhibitory effects of this treatment.

\section{Methods}

All studies were approved by the university committee on the use and care of animals. All studies were conducted on male Sprague Dawley rats obtained from Charles River (Portage, MI, USA), weighing 150-200 gs at the time of their arrival. All rats were given a minimum of one week to adapt to the stress of shipment before any experimental manipulations were initiated. All rats were maintained on a $12 \mathrm{~h} \mathrm{light/dark} \mathrm{schedule} \mathrm{and}$ were given food and water ad libitum. All animals were group housed (6/cage) for these experiments. Rats sacrificed in the morning were within $3 \mathrm{~h}$ of 'lights on' and those in the evening within $2 \mathrm{~h}$ of 'lights off', but always during the lights on period. Exogenous corticosterone was administered as a $100 \mathrm{mg}$ corticosterone/cholesterol pellet implanted subcutaneously under metofane anesthesia as described by Dallman et al. (2).

\section{Experimental Design}

These experiments involved the implantation of either $25 \%$ or $50 \%$ corticosterone/cholesterol pellets (100 $\mathrm{mg}$ total) in the experimental group, and cholesterol pellets $(100 \mathrm{mg})$ in the control animals on day 0. Animals were sacrificed at 2 times, day 6 in the morning and evening. Each group consisted of 6 rats. At each time trunk blood and pituitaries were collected for hormonal assays, brains for glucocorticoid receptor assays and adrenals and thymuses for weight determination. Subsequent experiments examined these same measures on day 6 in the a.m. In the repeat $50 \%$ corticosterone pellet experiment, a total of 12 rats received corticosterone pellets and 12 rats received cholesterol pellets. Five days following the implantation of the pellets, half of each group was given dexamethasone $1.5 \mu \mathrm{g} / \mathrm{ml}$ overnight in their drinking water (water was changed at 16.00 ). The other half of the rats were given normal drinking water.

All rats were sacrificed the following morning. A repeat experiment for acute dexamethasone consisted of overnight dexamethasone administration in the drinking water $(1.5 \mu \mathrm{g} / \mathrm{ml})$ to 6 rats, overnight corticosterone administration in the drinking water $(200 \mu \mathrm{g} / \mathrm{ml})$ to 6 rats and normal drinking water in the control rats. All rats were sacrificed the following morning. A repeat experiment consisted of overnight dexamethasone administration in the drinking water $(1.5 \mu \mathrm{g} / \mathrm{ml})$ to 6 rats, overnight corticosterone administration in the drinking water $(200 \mu \mathrm{g} / \mathrm{ml})$ to 6 rats and normal drinking water in the control rats. Again, all rats were sacrificed the following morning and all hormone measures are from those time points.

In vivo experiments examining a.m. and p.m. stress responsiveness utilized a repeated measure design. Each animal was exposed to $30 \mathrm{~min}$ of a.m. and p.m. restraint (separated by 3 days) before implantation of the $50 \%$ corticosterone pellets. Blood for ACTH and corticosterone was obtained by tail nick into non-heparinized capillary tubes. Following the time 0 sample (corticosterone only), a drop of dilute heparin-saline $(1000 \mathrm{u} / \mathrm{ml})$ was placed over the cut. The 5 and $30 \mathrm{~min}$ samples were collected from the same nick. Immediately following filling of each capillary tube, the sample was transferred from the capillary tube into an EDTA solution to prevent clotting.

\section{Tissue processing}

Trunk blood was collected in $\mathrm{K}+$ EDTA containing tubes on ice, centrifuged immediately, the plasma separated and acidified with $1 \mathrm{~N} \mathrm{HCl}$, then frozen on dry ice. It was subsequently stored at $-70^{\circ} \mathrm{C}$ until extraction. Brains were removed from the skuil, dissected on ice into the following regions: hippocampus, cortex overlying the hippocampus, and hypothalamus. These regions were frozen immediately on dry ice and stored at $-70^{\circ} \mathrm{C}$ until the day of assay. To avoid contamination of the anterior lobe of the pituitary by intermediate lobe melanotrophs, the neurointermediate lobe of the pituitary was removed from the anterior lobe, and the portions of the anterior lobe contacting the intermediate lobe was discarded. The anterior lobe fragments were then frozen on dry ice and stored at $-70^{\circ} \mathrm{C}$ until extraction. For anterior pituitary in vitro challenge studies, anterior pituitaries from 3 animals were pooled, processed into single cell suspensions using collagenase treatment, and challenged with oCRF using the methods previously described (29). Aliquots of the single cell suspension containing 250,000 cells were incubated with either medium alone or $1 \mathrm{nM}$ oCRF for $60 \mathrm{~min}$ at $37^{\circ} \mathrm{C}$ under $95 \% \mathrm{O}_{2}, 5 \% \mathrm{CO}_{2}$. All samples were run in triplicate. At the end of the hour, the cell suspensions were centrifuged, the media collected for assay, and the the cells were extracted with GITC extraction described below. Thymuses were collected into 24 well microtiter plates with a small amount of isotonic saline, blotted on weighing paper, then weighed on the same day as the experiment. Adrenals were treated similarly; the outer capsule and fat was removed before weighing.

\section{Hormonal assays}

Plasma samples were extracted with Sep-Pak $\mathrm{C}_{18}$ cartridges using our previously described procedure (30). Samples were assayed for corticosterone using an RIA with our own antibody to corticosterone. This RIA is very specific for corticosterone and cross-reacts less than $2 \%$ with cortisol or 1l-deoxycorticosterone. The assay buffer is $50 \mathrm{mM}$ sodium phosphate containing $2.5 \%$ bovine serum albumin, $\mathrm{pH} 7.5$. Following extraction the samples are re-suspended in assay buffer and two dilutions, the equivalent of $2 \mu \mathrm{l}$ and $5 \mu \mathrm{l}$ of plasma are compared to determine which reads in the linear range of the curve. $\left[{ }^{3} \mathrm{H}\right]$ corticosterone was used as the radiolabeled ligand. Bound and free were separated by the addition of a charcoal:dextran mixture $(1 \%: 0.1 \%)$ and centrifugation at $3000 \times \mathrm{g}$ The assay sensitivity is $0.5 \mu \mathrm{g} / \mathrm{dl}$. Samples were assayed for ACTH by 2 methods, an RIA using our own antibody raised to ACTH 11-24, and the Allegro HS ACTH kit (Nichols Institute, San Juan Capistrano, CA. USA). Because the ACTH samples were extracted, $25 \mu \mathrm{l}$ aliquots containing the equivalent of $250 \mu \mathrm{l}$ of plasma that were resuspended in $0.1 \%$ HSA were diluted to $200 \mu \mathrm{l}$ using the equine serum zero standard provided 
by the kit. $\beta$-endorphin was assayed using the previously described assay $(24,25)$. This antibody recognizes fully both $\beta$-lipotropin and $\beta$-endorphin, and thus gives a reliable index of corticotrope secretion.

Anterior pituitaries were extracted using a guanidium-isothiocyanate (GITC) extraction. Tissue were homogenized through a $26 \mathrm{Ga}$ needle in $300 \mu \mathrm{l}$ of GT buffer (guadinium isothiocyanate (5M), $10 \mathrm{mM}$ EDTA, $50 \mathrm{mM}$ Tris, $8 \%$ mercaptoethanol). Five volumes of $4 \mathrm{M} \mathrm{LiCl}$ were added and the samples were precipitated overnight at $4{ }^{\circ} \mathrm{C}$. Following centrifugation. the supernatant containing proteins was further extracted by SepPak extraction, lyophilized and then assayed for ACTH using the radioimmunoassay previously described. (25) This assay utilizes an antibody raised to ACTH 11-24, which recognizes ACTH and larger molecular weight forms ( $22 \mathrm{~K}$ and POMC) but not alpha-MSH. The pellet containing nucleic acids was digested with $300 \mu \mathrm{l}$ of proteinase $\mathrm{K}(150 \mu \mathrm{g} / \mathrm{ml})$ solution. and then mRNA was precipitated in ethanol at $-20^{\circ} \mathrm{C}$ for subsequent POMC mRNA quantitation. Approximately $3 \mu \mathrm{g}$ of total RNA was loaded on a $1 \%$ agarose formaldehyde gel and electrophoreseded for $6-8 \mathrm{~h}$, then blotted onto Nytran membrane $(0.45 \mu \mathrm{M})$ overnight. Membranes were probed with a ${ }^{32} \mathrm{P}$ labeled cRNA probe transcribed from a full length rat POMC cDNA ( $960 \mathrm{bp}$. Eberwine) and apposed to autoradiographic film. Appropriate size bands on the X-ray film were quantitated by optical density and normalized to total ribosomal RNA, as determined by an ${ }^{35} \mathrm{~S}$ labeled ribosomal RNA probe of the same membrane, or normalized to P1B15 mRNA (corticosterone injection experiments).

A $2 \mathrm{~mm}$ section through the hypothalamus containing the paraventricular nucleus (PVN) was dissected using a brain block slice with subsequent removal of tissue lateral to the PVN. The hippocampus and frontal cortex were dissected from the region caudal to the hypothalamic slice. All tissue was frozen immediately on dry ice and stored at $-80^{\circ} \mathrm{C}$ until subsequent extraction. The RNA was extracted from the anterior pituitary, paired PVN, and one hippocampus from each animal using a guanidium isothiocyanate extraction (GITC). Tissues were homogenized in buffer containing $5 \mathrm{M}$ GITC, $10 \mathrm{mM}$ EDTA, $50 \mathrm{mM}$ Tris $\mathrm{HCl}(\mathrm{pH} 7.5), 8 \%$ $(\mathrm{v} / \mathrm{v}) \beta$-mercaptoethanol, then precipitated with 5 volumes of $4 \mathrm{M} \mathrm{LiCl}$ at $4^{\circ} \mathrm{C}$. The precipitates were pelleted by centrifugation and treated with proteinase $\mathrm{K}(100 \mu \mathrm{g} / \mathrm{ml}$ in $0.5 \%$ SDS, $50 \mathrm{mM}$ Tris $\mathrm{HCl})$ for $1-2 \mathrm{~h}$ at $37^{\circ} \mathrm{C}$. The samples were extracted by phenol-chloroform then precipitated in EtOH. Following EtOH precipitation, RNA samples from the PVN and the hippocampus were used in a RNAse protection assay as previously described (19). Briefly, A 751 bp fragment of the rat CRF CDNA (provided by A. Seasholtz) was transcribed to yield a $C R N A$ probe labeled with ${ }^{32} \mathrm{P}$-UTP. The rat glucocorticoid receptor clone spanning $450 \mathrm{bp}$ of the $3^{\prime}$ untranslated flanking sequence was used as a template for cRNA synthesis. The rat mineralocorticoid receptor DNA was a $550 \mathrm{bp}$ fragment of the $3^{\prime}$ translated and untranslated region. These probes were added to the respective hybridization mix (400 mM PIPES pH $6.4,0.4 \mathrm{M} \mathrm{NaCl}$ $1 \mathrm{mM}$ EDTA, $50 \%$ formamide) containing $1 / 3$ of the RNA extracted from paired PVN from each rat, or from one hippocampus of each rat. Hybridization takes place for $14-16 \mathrm{~h}$ at $55^{\circ} \mathrm{C}$. RNAse $\mathrm{A}, 10 \mu \mathrm{g} / \mathrm{ml}$ was added and incubated for $15-30 \mathrm{~min}$ at room temperature. RNAse is neutralized by addition of $1 \%$ SDS and proteinase $\mathrm{K}$ for $30 \mathrm{~min}$ at $37^{\circ} \mathrm{C}$ The samples were then precipitated in EtOH, resuspended in $20 \%$ formamide and separated on a $4 \%$ polyacrylamide gel. The gel was apposed to X-ray film (Kodak X-ar) and resulting bands quantified by densitometry.

\section{Glucocorticoid receptor assays}

For measurement of GR in brain, single point assays on one hippocampus and one cortex of each animal were performed using a saturating concentration of ligand $\left(10 \mathrm{nM}\left[{ }^{3} \mathrm{H}\right]\right.$-dexamethasone) to quantitate binding for each animal $(17,18,30) .500 \mathrm{nM}$ RU 26988 , a specific Type II (GR) agonist, was used to determine GR binding and $2.5 \mu \mathrm{M}$ corticosterone was used to determine non-specific binding. The other hippocampus and cortex from each animal of the same group were pooled for Scatchard plot binding data (experiment 1 only). For hypothalamus, single point assays alone were performed. For the actual binding assay, frozen regions were homogenized with 15 strokes in a hand held glass homogenizer in $10 \mathrm{mM}$ ice cold Tris buffer, pH 7.4, with $1 \mathrm{mM}$ EDTA, $10 \%$ glycerol, $20 \mathrm{mM}$ molybdate, and $1 \mathrm{mM}$ dithiothreitol. The homogenate was centrifuged at $40,000 \mathrm{rpm}$ in an ultracentrifuge with T I-50 rotor for $30 \mathrm{~min}$. then the cytosol (supernatant) was transferred with pasteur pipette to a glass test tube and remained on ice until addition of labeling ligand. For Scatchard plot analyses, an aliquot of the cytosol ( $100 \mu \mathrm{I})$ was incubated with increasing concentrations of $\left[{ }^{3} \mathrm{H}\right]$ dexamethasone $(0.1-10 \mathrm{nM})$ with and without $500 \mathrm{nM}$ RU 26988 (a specific Type II antagonist). Excess $(2.5 \mu \mathrm{M})$ corticosterone was used to determine specific total binding (MR plus GR). The samples plus radiolabelled ligand are incubated overnight at $0^{\circ} \mathrm{C}$ then bound $\left[{ }^{3} \mathrm{H}\right]$ ligand is separated from free by use of $\mathrm{LH}-20$ minicolumns ( $25 \%$ corticosterone peilet) or dextran coated charcoal (other experiments). The eluate from the minicolumn, which contains bound receptor-ligand complex, is collected directly into scintillation vials. scintillation cocktail is added and the samples are counted. Alternatively, following the addition of dextran coated charcoal, the incubation tubes were centrifuged, and the supernatant, containing bound receptor-ligand complex, was aliquotted into scintillation vials, and scintillation cocktail was added. All samples were run in triplicate, the triplicates were averaged, and fmoles bound were calculated. A small sample of the original cytosol was assayed for protein content with Bio Rad protein assay; the binding values are expressed as fmoles bound/mg protein.

\section{Acknowledgements}

The author would like to acknowledge the technical assistance of Christina Barr and Patti Lieberman, and the teaching assistance of Dr Seung P. Kwak for POMC northern gels analysis and the support of NIMH grants MH00427 and MH 45232.

\section{Accepted 14 September 1994}

\section{References}

1. Keller-Wood ME, Dallman MF. (1985). Corticosteroid inhibition of ACTH secretion. Endocrine Rev. 5: 1-24.

2. Dallman MF, Akana SF, Cascio ES, Darlington DN, Jacobson L, Levin N. (1987). Regulation of ACTH secretion: Variations on a theme of B. Recent Prog in Horm Res. 43: 113-173.

3. Krieger DT. (1979). Rhythms in CRH, ACTH and corticosteroids Endocr Rev. 1; 23-30.

4. Kovacs K, Makara GB. (1988). Corticosterone and dexamethasone act at different sites to inhibit adrenalectomy induced adrenocorticotropin hypersecretion. Brain Res. 474: 205-210.

5. McEwen BS, Weiss JM, Schwartz LS. (1968). Selective retention of corticosterone by limbic structures in the rat brain Nature. 220:911.

6. deKloet R, Wallach G, McEwen BS. (1975). Differences in corticosterone and dexamethasone binding to rat brain and pituitary, Endocrinology. 96: 598-605.

7. Gallagher TF, Yoshida K, Roffwarg HD, Fukishima DK, Weitzman ED, Hellman L. (1973). ACTH and cortisol secretory patterns in man. J Clin Endocrin Metab. 36: 1058-1073.

8. Retiene K. Zimmerman E, Schindler WJ, Neuenschwander J, Lipscomb HS. (1968). A correlative study of endocrine rhythms in rats. Acta Endocrinol (Kbh). 57: 615-622.

9. Graber AL, Givens J, Nocholson W, Island DP, Liddle DW. (1965). Persistence of diurnal rhythmicity in plasma ACTH concentrations in cortisol deficient patients. J Clin Endocrinol Metab. 25: 804-807.

10. Rubin RT, Poland RE, Lesser IM, Winston RA, Blodgett N. (1987). Neuroendocrine aspects of primary endogenous depression I. Cortisol secretory dynamics in patients and matched controls Arch Gen Psychiatry, 44: 328-336.

11. Halbreich U, Asnis GM, Schindledecker R, Zurnoff B, Nathan RS (1985). Cortisol secretion in endogenous depression I. Basal plasma levels. Arch Gen Psychiatry. 42: 909-914.

12. Pfohl B, Sherman B, Schlecter J, Stone R. (1985). Pituitary/adrenal axis rhythm disturbances in psychiatric patients. Arch Gen Psychiatry. 42: 897-903.

13. Carroll BJ, Curtis GC, Mendels J. (1976). Neuroendocrine regulation in depression I. Limbic system-adrenocortical dysfunction. Arch Gen Psychiatry. 33: 1039-1044.

14. Sachar EJ, Hellman L, Roffwarg HP, Halpern FS, Fukush DK. Gallagher TF. (1973). Disrupted 24 hour patterns of cortisol secretion in psychotic depressives. Arch Gen Psychiatry. 28: 19-24.

15. Spencer RL, Young EA, Choo PH, McEwen BS. (1990). Glucocorticoid Type I and Type II receptor binding: estimates of in vivo receptor number, occupancy and activation with varying levels of steroid. Brain Research. 514: 37-48. 
16. Meaney MJ, Viau V, Aitken DH, Bhatnagar S. (1988). Stress-induced occupancy and translocation of hippocampal glucocorticoid receptors. Brain Res. 44: 198-203.

17. Miller AH, Spencer RL, Pulera M, Kang S, McEwen BS, Stein M. (1992). Adrenal steroid receptor activation in rat brain and pituitary following dexamethasone: implications for the dexamethasone suppression test. Biol Psychiatry. 32: 850-869.

18. Spencer RL, Miller AH, Moday H, Stein M, McEwen BS. (1993). Diumal differences in basal and acute stress levels of Type $\mathbf{I}$ and Type Il adrenal steroid receptor activation in neural and immune tissues. Endocrinology. 133: 1941-1950.

19. Kwak SP, Young EA, Morano IM, Watson SJ, Akil H. (1992). Diurnal corticotropin-releasing hormone messenger ribonucleic acid variation in the paraventricular nucleus exhibits a rhythm distinct from that of plasma corticosterone. Neuroendocrinology. 55: 74-83.

20. Patel PD, Kwak SP, Herman JP, Young EA, Akil H, Watson SJ. (1991). Functional heterogeneity of type I and type II corticosteroid receptor expression in rat hippocampus. Proc Internat Symp Stress Reproduc. (in press).

2I. Reul JMH, deKloet ER. (1985). Two receptor systems for corticosterone in rat brain: Microdistribution and differential occupation. Endocrinology. 117: 2505-2511.

22. Reul JMH, van den Bosch FR, de Kloet ER. (1987). Relative occupation of type-I and type-II corticosteroid receptors in rat brain following stress and dexamethasone treatment: functional implications. J Endocrinol. 115: 459-467.

23. Herman JP, Patel PD, Akil H, Watson SJ. (1989). Localization and regulation of glucocorticoid and minerolcorticoid receptor mRNAs in the hippocampal formation of the rat. Mol Endocrinol. 3: 1886-1894.
24. Reul JMH, Pearce PT, Funder JW, Krozowski ZS. (1989). Type I and Type II corticosteroid receptor gene expression in the rat: effects of adrenalectomy and dexamethasone administration. Molec Endocrinol. 3: 1674-1680.

25. Reul JHM, van den Bosch FR, de Kloet ER. (1987). Differential response of Type I and Type II corticosteroid receptors to changes in plasma steroid levels and circadian rhythmicity. Neuroendocrinology. 45: $407-412$

26. Sapolsky RM. Krey LC, McEwen BS. (1984). Stress down-regulates glucocorticoid receptors in a site-specific manner. Endocrinology. 114: 287-292.

27. Sawchenko PE. (1987). Adrenalectomy-induced enhancement of CRf and vasopressin immunoreactivity in parvocellular neurosecretory neurons: anatomic, peptide and steroid specificity. J Neurosei. 7: $1093-1106$.

28. Akana SF, Scribner KA, Bradbury MJ, Strack AM, Walker CD, Dallman MF. (1992). Feedback sensitivity of the rat hypothalamopituitary-adrenal axis and its capacity to adjust to exogenous corticosterone. Endocrinology. 131: 585-594.

29. Young EA, Akil H. (1985). CRF stimulation of ACTH/betaendorphin release: Effect of acute and chronic stress. Endocrinology. 117: $23-30$.

30. Cahill CA, Matthews JD, Akil H. (1983). Human plasma $\beta$-endorphin-like peptides: A rapid, high recovery extraction technique and validation of radioimmunoassay. J Clin Endocrinol Metab. 56: 992-997.

31. Young EA, Spencer RL. McEwen BS. (1990). Changes at Multiple levels of the Hypothalamic Pituitary Adrenal Axis Following Repeated ECS. Psychoneuroendocrinology. 15: 165-172. 